\title{
Stationary Reference Frame Position Sensorless Control Based on Stator Flux Linkage and Sinusoidal Current Tracking Controller for IPMSM
}

\author{
Ryota Takahashi* Student Member, Kiyoshi Ohishi* Fellow \\ Yuki Yokokura* Member, Hitoshi Haga* Member \\ Tenjiroh Hiwatari* Student Member
}

(Manuscript received Feb. 29, 2016, revised Sep. 30, 2016)

\begin{abstract}
Generally, standard direct torque control (DTC) does not require fine current responses from the current controller because the torque and flux of a DTC-based drive are controlled by a closed-loop system without current loops. It is often difficult for the standard DTC to achieve the desired current regulation and fine harmonic current disturbance suppression performancew. In order to overcome these problems, this paper proposes a new stationary reference frame position sensorless control system based on stator flux linkage estimation, and a new sinusoidal current tracking controller. In this paper, the current control performance of IPMSMs using the proposed sinusoidal current tracking controller is evaluated through numerical simulation and experiments. Finally, using the proposed sinusoidal current tracking controller, the effectiveness of the proposed stationary reference frame position sensorless control system with the stator flux control method is confirmed through experimental results.
\end{abstract}

Keywords: IPMSM, position sensorless control, disturbance suppression characteristics, stationary reference frame, sinusoidal tracking current controller

\section{Introduction}

Internal permanent magnet synchronous motors (IPMSMs) have been applied for motors in electric vehicles and various industrial applications. Recently, to reduce the size and cost of the motor drive systems, position sensorless control methods have been studied extensively. Direct torque control (DTC) has often used to its position sensorless control based on stator flux estimation ${ }^{(1)-(4)}$. DTC has the merits of both fast torque response and low sensitivity to inductance variations. Hence, DTC has been used in many types of AC motor.

DTC has many regulation methods of stator flux and motor torque. DTC can have a fast torque response. The standard type of DTC uses both a switching table of space voltage vector and hysteresis comparator of torque and flux ${ }^{(1)}$. Other type of DTC is called Reference Flux Vector Calculator DTC (RFVC-DTC) $^{(2)-(4)}$. RFVC-DTC can have a fine and smooth torque response without torque ripple. In RFVC-DTC, the torque error is converted into the torque angle information by PI torque controller. Its voltage reference is determined by the torque angle information. Generally, the standard DTC and RFVC-DTC do not use the current regulated and do not regulate the motor current directly. Since IPMSM is driven by motor current, DTC should be regulated by the motor current. Therefore, the sensorless control method having the PI current controller has been realized ${ }^{(5)(6)}$, whose name is stator flux vector control (SFVC). In this case, its current controller is located on the rotating reference frame.

\footnotetext{
* Nagaoka University of Technology

1603-1, Kamitomioka-machi, Nagaoka, Niigata 940-2188, Japan
}

Standard DTC, RFVC-DTC and SFVC have the fine torque tracking performance. However, since the standard DTC and RFVC-DTC need not have current controller having a fine current response of primary frequency, the standard DTC and RFVC-DTC sometimes can not have a fine harmonic current disturbance suppression performance.

On condition of primary frequency, its d-q current information in rotating reference frame is equal to its $\alpha-\beta$ current information in stationary reference frame ${ }^{(7)}$. On the other hand, in case of harmonic frequency, the d-q current control does not often have the desired performance.

Moreover, the current control performance of IPMSMs using the new sinusoidal tracking current controller is evaluated by the numerical simulation results and experimental results.

The current control in the stationary reference frame can suppress the harmonic current better than current control in the rotating reference frame. Thus, robust performance against the harmonic current is obtained by control of the stationary frame.

In order to obtain robust performance, this paper proposes that the proposed stationary reference frame position sensorless control is accomplished with a new current control system in the $\alpha-\beta$ stationary frame.

This paper confirms the validity of the proposed method by using the experimental results.

\section{Sinusoidal Current Tracking Control}

2.1 Nomeclature Definition diagram of coordinates is shown in Fig. 1. Here, superscrips and symbol and abbreviations are shown as follow; 


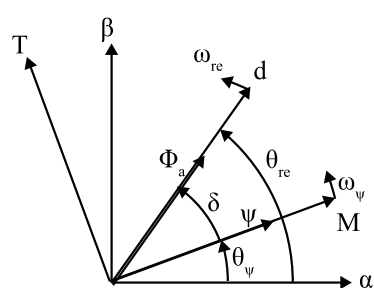

Fig. 1. Coordinate of stationary reference frame

\section{Superscripts}

: Estimated quantities

ref: Reference quantities

res: Response value

dis: Disturbance

Symbol and Abbreviations

$v_{d}, v_{q}$ : Stator q- and d-axes voltages.

$v_{\alpha}, v_{\beta}$ : Stator $\alpha$ - and $\beta$-axes voltages.

$v_{M}, v_{T}$ : Stator M- and T-axes voltages.

$i_{d}, i_{q}:$ Stator q- and d-axes currents.

$i_{\alpha}, i_{\beta}$ : Stator $\alpha$ - and $\beta$-axes currents.

$i_{M}, i_{T}$ : Stator M- and T-axes currents.

$R_{a}:$ Stator resistance.

$\phi_{a}$ : Permanent magnet flux linkage.

$L_{d}, L_{q}$ Stator d- and q-axes inductances.

$p$ : Derivative operator.

$P$ : Pole pairs.

$V_{d c}$ : DC link voltage.

$\psi, \psi_{\alpha}, \psi_{\beta}$ : Stator $\alpha$ - and $\beta$-axes flux.

$\psi_{M}, \psi_{T}$ : Stator M- and T-axes flux.

$T$ : Torque.

$\omega_{r e}, \theta_{r e}$ : Electrical angular velocity and position.

$\omega_{r m}, \theta_{r m}$ : Mechanical angular velocity and position.

$\omega_{\psi}, \theta_{\psi}$ : Stator flux angular velocity and position.

$\omega_{c}$ : Pole of current control system.

$\omega_{s}$ : Pole of speed control system.

$\omega_{f}$ : Pole of flux control system.

$\omega_{L P F}$ : Pole of low pass filter.

$\omega_{B}$ : Pole of band pass filter.

$J_{M}$ : Inertia moment.

$E_{e x}$ : Extended electromotive force.

2.2 Stationary Reference Frame Model of IPMSM

In this paper, the current control system for IPMSM is designed by sinusoidal tracking controller in the stationary reference frame (i.e., $\alpha-\beta$ reference frame). At first, the circuit equations $d-q$ reference frame are given in (1). Using the rotating frame transformation, (1) is converted into (3), which is the voltage equation in $\alpha-\beta$ reference frame.

$$
\begin{aligned}
& {\left[\begin{array}{c}
v_{d} \\
v_{q}
\end{array}\right]=} {\left[\begin{array}{cc}
R_{a}+p L_{d} & -\omega_{r e} L_{q} \\
\omega_{r e} L_{d} & R_{a}+p L_{q}
\end{array}\right]\left[\begin{array}{c}
i_{d} \\
i_{q}
\end{array}\right] } \\
&+\left[\begin{array}{c}
0 \\
\omega_{r e} \phi_{a}
\end{array}\right] \ldots \ldots \ldots \ldots \ldots \ldots \ldots \\
& E_{e x}=\left(L_{d}-L_{q}\right)\left(\omega_{r e} i_{d}+p i_{q}\right)+\omega_{r e} \phi_{a} \ldots \ldots \ldots \\
& {\left[\begin{array}{c}
v_{\alpha} \\
v_{\beta}
\end{array}\right]=\left[\begin{array}{cc}
R_{a}+p L_{\alpha} & -p L_{\alpha \beta} \\
-p L_{\alpha \beta} & R_{a}+p L_{\beta}
\end{array}\right]\left[\begin{array}{c}
i_{\alpha} \\
i_{\beta}
\end{array}\right] } \\
&+\omega_{r e}\left[\begin{array}{cc}
2 L_{\alpha \beta} & L_{\alpha}-L_{\beta} \\
L_{\alpha}-L_{\beta} & -2 L_{\alpha \beta}
\end{array}\right]\left[\begin{array}{c}
i_{\alpha} \\
i_{\beta}
\end{array}\right]
\end{aligned}
$$

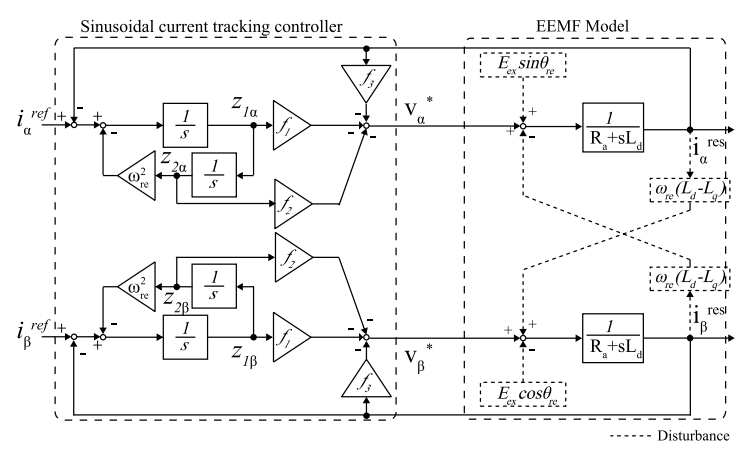

Fig. 2. Structure of current control system and EEMF model

$$
+\omega_{r e} \phi_{a}\left[\begin{array}{c}
-\sin \theta_{r e} \\
\cos \theta_{r e}
\end{array}\right]
$$

where

$$
\begin{aligned}
& L_{\alpha}=\frac{1}{2}\left[L_{d}+L_{q}+\left(L_{d}-L_{q}\right) \cos 2 \theta_{r e}\right] \\
& L_{\beta}=\frac{1}{2}\left[L_{d}+L_{q}-\left(L_{d}-L_{q}\right) \cos 2 \theta_{r e}\right] \\
& L_{\alpha \beta}=-\frac{1}{2}\left[\left(L_{d}-L_{q}\right) \sin 2 \theta_{r e}\right] \ldots \ldots \ldots
\end{aligned}
$$

In this paper, an extended electromotive force (EEMF) model $^{(8)}$ is used for design of current-controller. The EEMF circuit equations of IPMSM in $d-q$ reference frame are given by (7).

$$
\left[\begin{array}{l}
v_{d} \\
v_{q}
\end{array}\right]=\left[\begin{array}{cc}
R_{a}+p L_{d} & -\omega_{r e} L_{q} \\
\omega_{r e} L_{q} & R_{a}+p L_{d}
\end{array}\right]\left[\begin{array}{c}
i_{d} \\
i_{q}
\end{array}\right]+\left[\begin{array}{c}
0 \\
E_{e x}
\end{array}\right]
$$

Using the rotating frame transformation, (7) is converted into (8), which is the EEMF-type voltage equation in $\alpha-\beta$ reference frame. Using (8), the plant model of sinusoidal current tracking controller is defined as shown in Fig. 2.

$$
\begin{aligned}
{\left[\begin{array}{c}
v_{\alpha} \\
v_{\beta}
\end{array}\right]=} & {\left[\begin{array}{cc}
R_{a}+p L_{d} & \omega_{r e}\left(L_{d}-L_{q}\right) \\
-\omega_{r e}\left(L_{d}-L_{q}\right) & R_{a}+p L_{d}
\end{array}\right]\left[\begin{array}{c}
i_{\alpha} \\
i_{\beta}
\end{array}\right] } \\
& +E_{e x}\left[\begin{array}{c}
-\sin \theta_{r e} \\
\cos \theta_{r e}
\end{array}\right] \ldots \ldots \ldots \ldots \ldots \ldots \ldots
\end{aligned}
$$

2.3 Design of Current Control System based on Sinusoidal Current Tracking Controller In $\alpha-\beta$ reference frame, the current controller must have the internal model of sinusoidal wave function, such as co-sine function, as shown in Fig. 2.

In this paper, the EEMF model is used for design of current controller, and the internal model of current regulator is co-sine function. The proposed current control system based on EEMF model is realized as shown in Fig. 2. In Fig. 2, the coupling EEMF component are treated as the disturbances for the current control system.

The transfer function from $i_{\alpha}^{\text {ref }}$ to $i_{\alpha}^{\text {res }}$ is given by (9).

$$
\begin{aligned}
& G_{r e f r e s}=\frac{i_{\alpha}^{r e s}}{i_{\alpha}^{r e f}}=\frac{-b_{1} s-b_{0}}{s^{3}+a_{2} s^{2}+a_{1} s+a_{0}} \\
& a_{0}=\frac{1}{L_{d}}\left(R_{a} \omega_{r e}^{2}+f_{3} \omega_{r e}^{2}-f_{2}\right) \ldots \ldots \ldots \\
& a_{1}=\left(\omega_{r e}^{2}-\frac{f_{1}}{L_{d}}\right) \ldots \ldots \ldots \ldots \ldots
\end{aligned}
$$




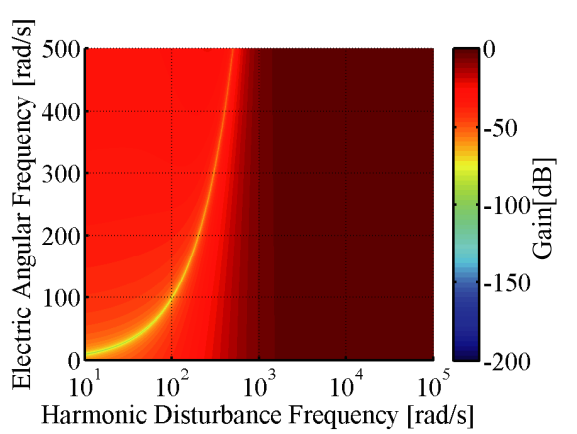

(a) Disturbance suppression characteristics of the positive-phase harmonic components

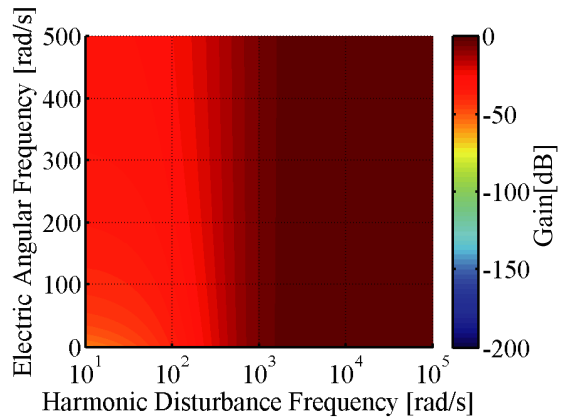

(b) Disturbance suppression characteristics of the negative-phase harmonic components

Fig. 3. Disturbance suppression characteristics using dq PI current control

$$
\begin{aligned}
& a_{2}=\frac{R_{a}}{L_{d}}+\frac{f_{3}}{L_{d}} \\
& b_{0}=\frac{f_{2}}{L_{d}} \cdots \cdots \\
& b_{1}=\frac{f_{1}}{L_{d}} \cdots \cdots
\end{aligned}
$$

The current control system is designed by using (9). On the basis of the poles placement method, the poles of the sinusoidal current tracking controller are designed so as to have the desired roots. The feedback gains of the sinusoidal current tracking controller are given by (15)-(17). Using these gains, the poles of the current control system are arranged in multiple roots in the band. The zero also has a stable placement. Therefore, the current control system has stable operation using the feedback gains of (15)-(17).

$$
\begin{aligned}
& f_{1}=L_{d}\left(\omega_{r e}^{2}-3 \omega_{c}^{2}\right) \cdots \\
& f_{2}=L_{d}\left(3 \omega_{c} \omega_{r e}^{2}-\omega_{c}^{3}\right) \\
& f_{3}=3 L_{d} \omega_{c}-R_{a} \ldots .
\end{aligned}
$$

2.4 Evaluation based on Extended Transformation of the Disturbance Suppression Characteristics Using the extended transfer function ${ }^{(9)(10)}$, the both disturbance suppression characteristics of $\mathrm{d}-\mathrm{q}$ PI current control and $\alpha-\beta$ sinusoidal current control are evaluated in this paper by using the extended transfer function, which is introduced in Appendix of this paper. The extended transfer function can evaluate the both frequency characteristics of $\mathrm{d}-\mathrm{q}$ PI regulator and $\alpha-\beta$ sinusoidal regulator on the positive and negative harmonics phase components. Here, $\mathrm{j}$ is the complex coefficient. The transfer function from $i_{\alpha}^{d i s}$ to $i_{\alpha}^{\text {res }}$ in d-q PI regulator is given by (18).

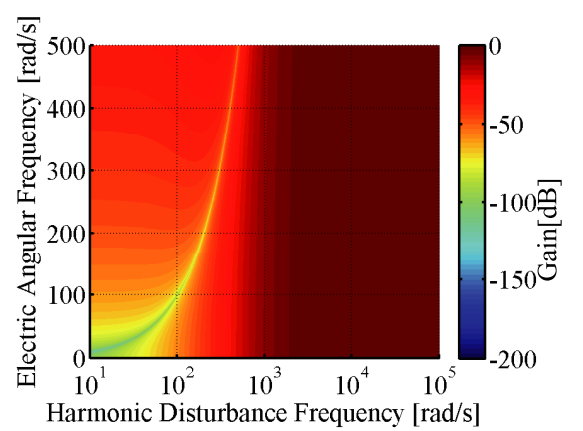

(a) Disturbance suppression characteristics of the positive-phase harmonic components

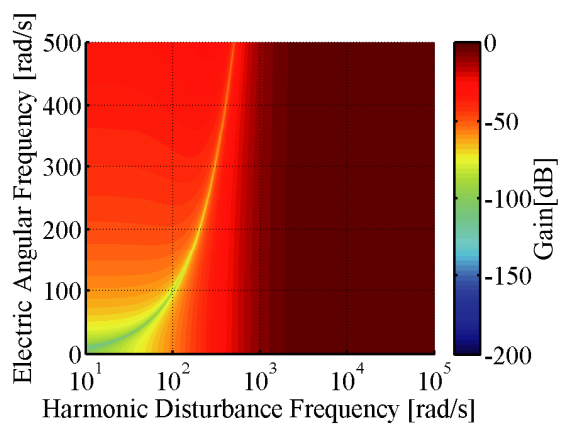

(b) Disturbance suppression characteristics of the negative-phase harmonic components

Fig. 4. Disturbance suppression characteristics using $\alpha$ $\beta$ sin current control

$$
\begin{aligned}
& G_{d q-P I}^{d i s}=\frac{i_{\alpha \beta}^{r e s}}{i_{\alpha \beta}^{d i s}}=\frac{-s^{2}+n_{1} s+n_{0}}{s^{2}+m_{1} s+m_{0}} \\
& m_{0}=\frac{K_{I}-j\left(R_{a}+K_{P}\right) \omega_{r e}}{L_{d}} \ldots \ldots \\
& m_{1}=\frac{\left(R_{a}+K_{P}-j L_{d} \omega_{r e}\right)}{L_{d}} \ldots \ldots \\
& n_{0}=\frac{j R_{a} \omega_{r e}}{L_{d}} \ldots \ldots \ldots \ldots \ldots \\
& n_{1}=\frac{-R_{a}+j L_{d} \omega_{r e}}{L_{d}} \ldots \ldots \ldots \ldots
\end{aligned}
$$

The transfer function from $i_{\alpha}^{d i s}$ to $i_{\alpha}^{r e s}$ in the $\alpha-\beta$ sinusoidal control is given by (23).

$$
\begin{aligned}
& G_{\alpha \beta-s i n}^{d i s}=\frac{i_{\alpha \beta}^{r e s}}{i_{\alpha \beta}^{d i s}}=\frac{-s^{3}-q_{2} s^{2}-q_{1} s-q_{0}}{s^{3}+a_{2} s^{2}+a_{1} s+a_{0}} \ldots \ldots \ldots \\
& q_{0}=\frac{R_{a}}{L_{d}} \omega_{r e}^{2} \\
& q_{1}=\omega_{r e}^{2} \\
& q_{2}=\frac{R_{a}}{L_{d}}
\end{aligned}
$$

Using (18) and (23), each bode diagram of d-q PI regulator and $\alpha-\beta$ sinusoidal regulator is obtained for the positive-phase disturbance suppression characteristics, as shown in Fig. 3(a) and Fig. 4(a). In Fig. 3(a) and Fig. 4(a), the fundamental frequency performance of $\mathrm{d}$-q PI regulator is equivalent equal to that of $\alpha-\beta$ sinusoidal regulator. However, the harmonic disturbance suppression performance of $\alpha-\beta$ sinusoidal regulator is slightly better than that of $\mathrm{d}-\mathrm{q}$ PI regulator. Comparing the two disturbance suppression characteristics, the 


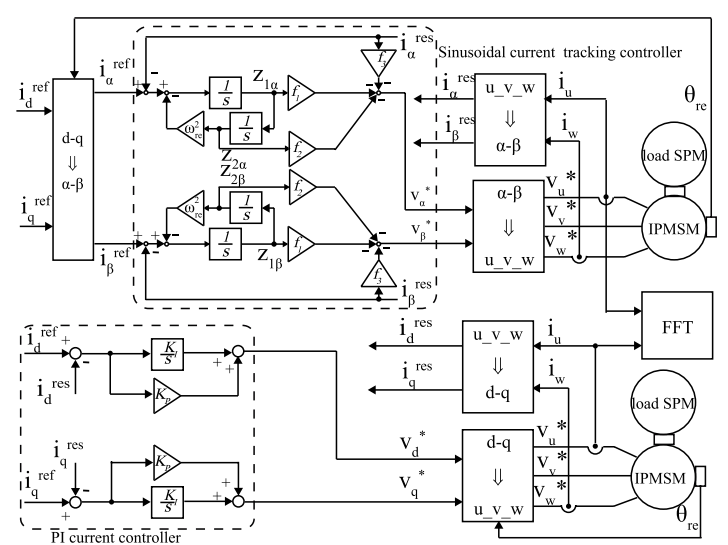

Fig. 5. Experimental system for evaluation on disturbance suppression performance d-q PI current regulator and $\alpha-\beta$ sinusoidal current regulator

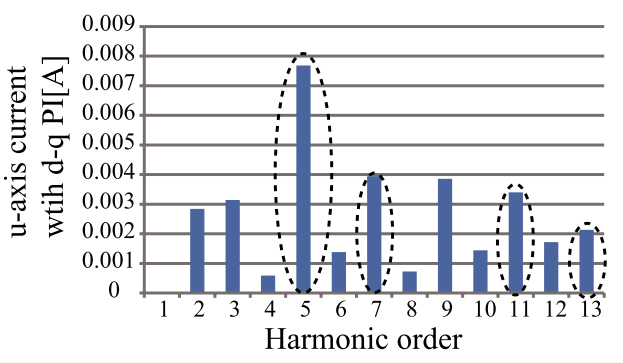

(a) FFT analysis u-phase current responses with d-q PI regulator.

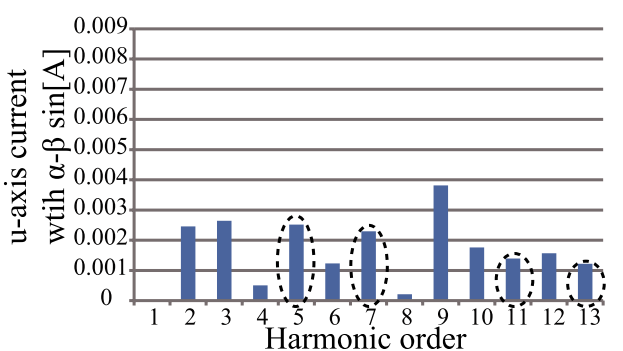

(b) FFT analysis results u-phase responses with $\alpha-\beta$ sinusoidal regulator.

Fig. 6. Experimental results of u-phase current FFT analysis

harmonic disturbance suppression performance of the $\alpha-\beta$ sinusoidal regulator is one order higher than that of the d-q PI regulator. Therefore, the harmonic disturbance suppression performance of the $\alpha-\beta$ sinusoidal regulator is slightly better compared with the d-q PI regulator.

Similarly, Fig. 3(b) and Fig. 4(b) show each bode diagram of the negative phase disturbance suppression characteristics, respectively. The negative-phase harmonic disturbance rejection performance of $\alpha-\beta$ sinusoidal regulator is better than that of d-q-PI regulator.

As the result, the effectiveness of $\alpha-\beta$ sinusoidal controller is confirmed through the experimental results of Fig. 6. The rated values and specifications of tested motor are shown in Table 1, respectively. In the experiment, the motor torque current is maintained at iq $=1 \mathrm{~A}$, which is $40 \%$ load. The motor speed is maintained at $100 \mathrm{rpm}$. In order to confirm the disturbance suppression characteristics, the experimental results are shown in Fig. 6(a) and Fig. 6(b). The robust performance of $\alpha \beta-\sin$ is better than dq-PI. 7th and 13th are a positive phase disturbance. Because the order of the transfer
Table 1. Rated values and specifications of tested motor

\begin{tabular}{|c|c|}
\hline$R_{a}$ & $2.8[\Omega]$ \\
\hline$L_{d}$ & $28[\mathrm{mH}]$ \\
\hline$L_{q}$ & $70[\mathrm{mH}]$ \\
\hline$P$ & 3 \\
\hline$J_{M}$ & $1.152^{2} 10^{-3}\left[\mathrm{kgm}^{2}\right]$ \\
\hline Carrier frequency PWM Inverter & $10[\mathrm{kHz}]$ \\
\hline Rated current of u-phase & $3[\mathrm{~A}]$ \\
\hline Rated speed & $1800[\mathrm{rpm}]$ \\
\hline Rated power & $750[\mathrm{~W}]$ \\
\hline
\end{tabular}

Table 2. Specification of tested speed control system

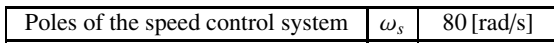
\begin{tabular}{|l|l|l|}
\hline Poles of the current control system & $\omega_{c}$ & $2000[\mathrm{rad} / \mathrm{s}]$ \\
\hline
\end{tabular}

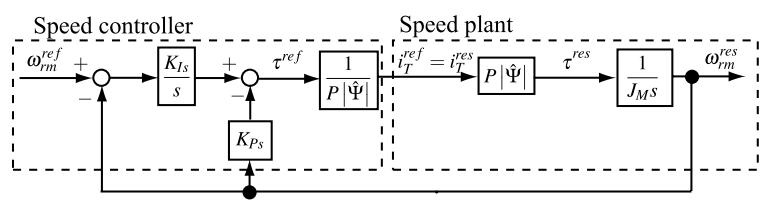

Fig. 7. Speed control system using I-P speed controller

function of $\alpha \beta-\sin$ is high, $\alpha \beta-\sin$ can reduce the positive phase disturbance better than the dq-PI. 5th and 11th is a negative phase disturbance. $\alpha \beta-\sin$ can be reduced more than dq-PI because $\alpha \beta-\sin$ can be suppressed even for negative phase. From the above results, the current control system using the sinusoidal tracking controller can reduce the current harmonics better than the current control system using the PI controller. Therefore, the current control system using the sinusoidal tracking controller is expected to suppress torque ripple and motor noise generated by the structure of the winding and the space harmonic flux. The disturbance suppression characteristics of the current control system using the sinusoidal tracking controller in the modified IPMSM can also be found in the Appendix.

2.5 Experimental Results of Sinusoidal Current Tracking Controller with Position Sensor Using the $\alpha-\beta$ sinusoidal current controller, the speed control system with position sensor is constructed. The transfer function from $\omega_{r m}^{r e f}$ to $\omega_{r m}^{r e s}$ is given by (27).

$$
G_{\text {refres }}=\frac{\omega_{r m}^{r e s}}{\omega_{r m}^{r e f}}=\frac{K_{I s}}{J_{m} s^{2}+K_{P s} s+K_{I s}}
$$

where $K_{P S}$ and $K_{I S}$ represent the proportional and integral gains of the speed controller. The speed controller is an I-P type controller. The speed control system is shown in Fig. 6. $K_{P s}$ and $K_{I s}$ are calculated by the use of (27) and the pole placement method. Using (9) and (27), the specifications of the tested current control system and the tested speed control system are designed as shown in Table 2.

Figure 8 shows the experimental results of speed control system based on $\alpha-\beta$ sinusoidal current controller with position sensor. The proposed speed control system based on $\alpha-\beta$ sinusoidal current controller has good responses.

\section{Position Sensorless Control based on $\alpha \beta$-sin Current Controller}

3.1 Sensorless Control Method of Torque (Method 1)

Here, the principle of proposed position sensorless control is presented in Fig. 9. The motor torque of IPMSM is defined 

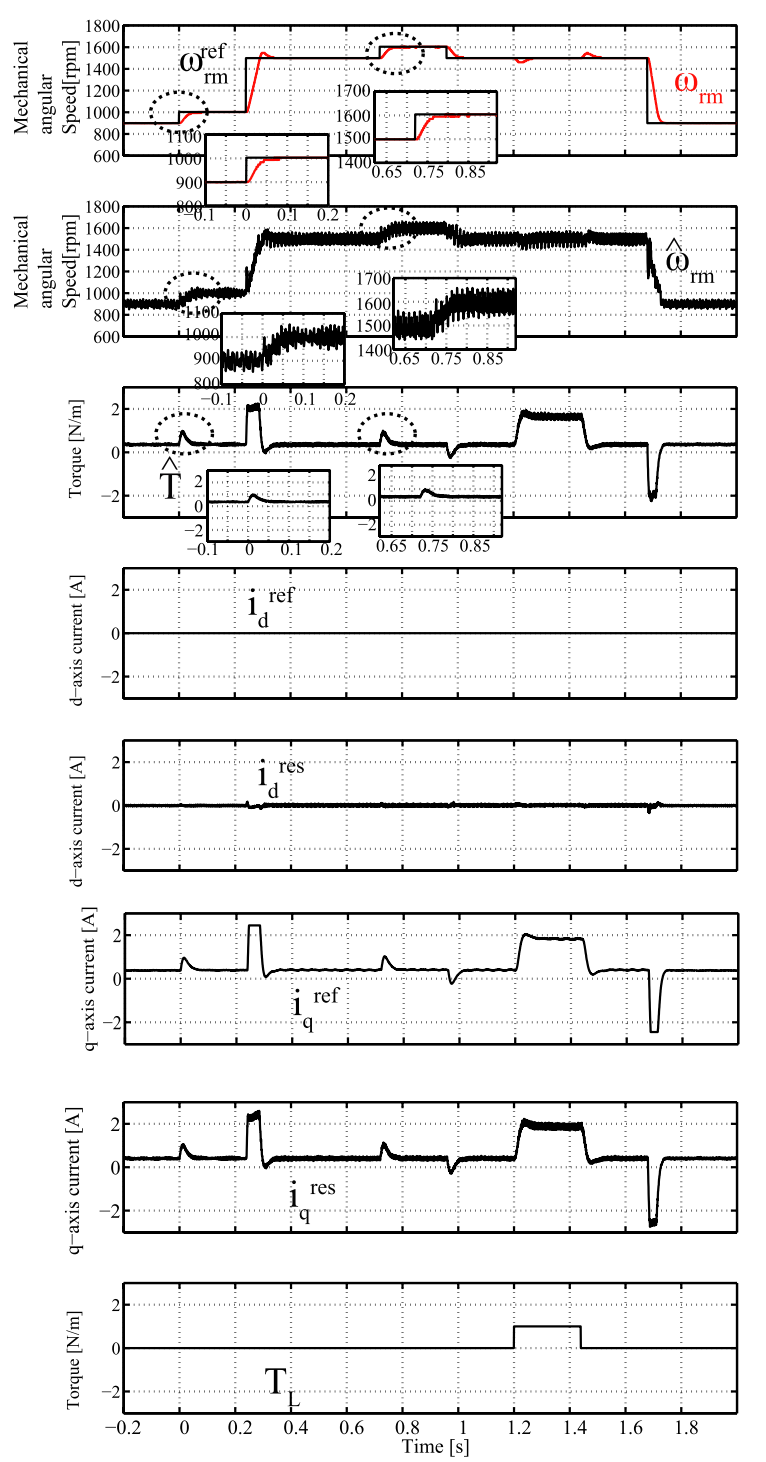

Fig. 8. Experimental results of speed step response using speed control system based on sinusoidal current tracking controller with position sensor

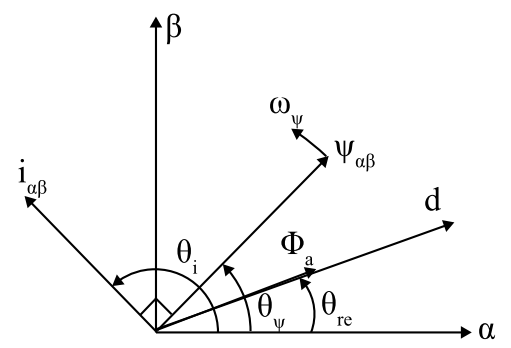

Fig. 9. Coordinate of position-sensorless control in stationary reference frame

by (28). The stator flux linkage vector is estimated by using (29) and (30) ${ }^{(11)(12)}$.

$$
\begin{aligned}
T & =P \psi * i^{r e f} \\
& =P\left(\psi_{\alpha} i_{\beta}-\psi_{\beta} i_{\alpha}\right) \cdots \ldots \ldots \\
\hat{\psi}_{\alpha} & =\int_{0}^{t}\left(v_{\alpha}^{*}-R_{a} i_{\alpha}\right) d t+\left.\hat{\psi}_{\alpha}\right|_{t=0} \\
\hat{\psi}_{\beta} & =\int_{0}^{t}\left(v_{\beta}^{*}-R_{a} i_{\beta}\right) d t+\left.\hat{\psi}_{\beta}\right|_{t=0} .
\end{aligned}
$$

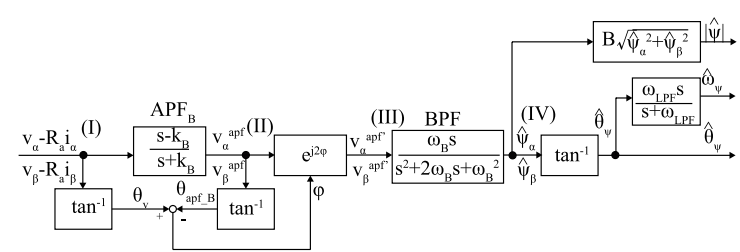

Fig. 10. Stator flux estimator using APF based on BPF

The phase $\theta_{\psi}$ in the $\alpha$-axis, its angular speed $\omega_{\psi}$, and the absolute value $|\psi|$ of the stator interlinkage magnetic flux vector are calculated using (31)-(33), respectively. The angular frequency of the stator flux is calculated by the quasidifferentiate of the phase of the stator flux. This paper uses $\omega_{L P F}$ in Fig. 10 because the quasi-differentiate is needed for the differential operation and LPF. The motor torque current reference $i^{r e f}$ is defined in (34). $\theta_{i}$ is the motor current phase of $\alpha$-axis, which is given by (35). Using (34) and (35), this paper proposes that the $\alpha \beta$-axis current references are calculated by using (36) and (37). As the results, this paper proposes a new stationary reference frame position sensorless control based on sinusoidal tracking current controller for IPMSM.

$$
\begin{aligned}
\hat{\theta}_{\psi} & =\tan ^{-1} \frac{\hat{\psi}_{\beta}}{\hat{\psi}_{\alpha}} \ldots \\
\hat{\omega}_{\psi} & =\frac{s \omega_{L P F}}{s+\omega_{L P F}} \hat{\theta}_{\psi} \\
|\hat{\psi}| & =\sqrt{\hat{\psi}_{\alpha}^{2}+\hat{\psi}_{\beta}^{2}} \ldots \\
i^{r e f} & =\frac{T^{r e f}}{P|\hat{\psi}|} \ldots \ldots \\
\hat{\theta}_{i} & =\hat{\theta}_{\psi}+\frac{\pi}{2} \cdots \cdots \\
i_{\alpha}^{r e f} & =i^{r e f} \cos \hat{\theta}_{i} \cdots \\
i_{\beta}^{r e f} & =i^{r e f} \sin \hat{\theta}_{i} \cdots
\end{aligned}
$$

3.2 Stator Flux Estimation of Using APF based on BPF (29) and (30) can not be calculated in the actual system because (29) and (30) have a complete integration calculation process. In order to overcome this problem, this paper uses the stator flux estimation of using the all pass filter (APF) based on band pass filter (BPF) ${ }^{(13)(14)}$. Stator flux estimation using APF based on BPF is shown in Fig. 9. The coordinate of stator flux estimator with APF based on BPF is shown in Fig. 10.

(I)

$$
\begin{aligned}
u_{\alpha} & =v_{\alpha}-R_{a} i_{\alpha} \ldots \ldots \ldots \ldots \ldots \ldots \ldots \ldots \ldots \ldots \ldots \ldots \ldots \ldots \ldots \ldots \ldots \ldots \ldots \ldots \ldots \ldots \ldots
\end{aligned}
$$

(II)

This paper uses the APF whose transfer function of is shown in (40).

$$
\begin{gathered}
G_{A P F}=\frac{s-k_{B}}{s+k_{B}} \\
v_{\alpha}^{a p f}=G_{A P F} u_{\alpha} \\
v_{\beta}^{a p f}=G_{A P F} u_{\beta}
\end{gathered}
$$

where $v_{\alpha}^{a p f}$ and $v_{\beta}^{a p f}$ are the value after the APF. Here, $k_{B}$ is 
determined as shown in (43).

$$
k_{B}=\omega_{B}
$$

In this paper, using (43), the phase characteristics is shifted to $-\frac{\pi}{2}$ degrees.

(III)

The drift occurs when the stator flux is estimated by (29) and (30). BPF is used to avoid the drift. However, the phase characteristic of the estimated value of the stator flux is changed by the BPF. Therefore, it is necessary to use (44) in order to obtain the phase characteristic that is equal to an ideal integrator.

$$
G_{A P F_{\text {ideal }}}=\frac{s+k_{B}}{s-k_{B}}
$$

However, (44) has an unstable pole. In order to realize (44), this paper used a vector rotator. The description of a vector rotator is shown below.

$$
\theta_{v}=\tan ^{-1} \frac{u_{\beta}}{u_{\alpha}}
$$

The output vector phase of APF is shown in (46).

$$
\theta_{a p f_{B}}=\tan ^{-1} \frac{v_{\beta}^{a p f}}{v_{\alpha}^{a p f}} .
$$

The vector rotator is shifted to $\varphi=\theta_{v}-\theta_{a p f_{B}}$. The rotator is described as shown in (47).

$$
\left[\begin{array}{c}
v_{\alpha}^{a p f^{\prime}} \\
v_{\beta}^{a p f^{\prime}}
\end{array}\right]=\left[\begin{array}{cc}
\cos 2 \varphi & -\sin 2 \varphi \\
\sin 2 \varphi & \cos 2 \varphi
\end{array}\right]\left[\begin{array}{c}
v_{\alpha}^{a p f} \\
v_{\beta}^{a p f}
\end{array}\right]
$$

where $v_{\alpha}^{a p f^{\prime}}$ and $v_{\beta}^{a p f^{\prime}}$ are the value after a vector rotator.

(IV)

As the result, using APF based on BPF, the stator flux linkage is estimated without phase error.

$$
\hat{\psi}_{\alpha}=\frac{\omega_{B} s}{s^{2}+2 \omega_{B} s+\omega_{B}^{2}} v_{\alpha}^{a p f^{\prime}}
$$

$$
\begin{aligned}
& \hat{\psi}_{\beta}=\frac{\omega_{B} s}{s^{2}+2 \omega_{B} s+\omega_{B}^{2}} v_{\beta}^{a p f^{\prime}} \ldots \\
& B=\frac{\sqrt{\left(\omega_{r e}^{2}-\omega_{B}^{2}\right)^{2}+4 \omega_{r e}^{2} \omega_{B}^{2}}}{\omega_{B} \omega_{r e}^{2}} \\
& |\hat{\psi}|=B \sqrt{\hat{\psi}_{\alpha}^{2}+\hat{\psi}_{\beta}^{2}} \ldots \ldots \ldots \ldots
\end{aligned}
$$

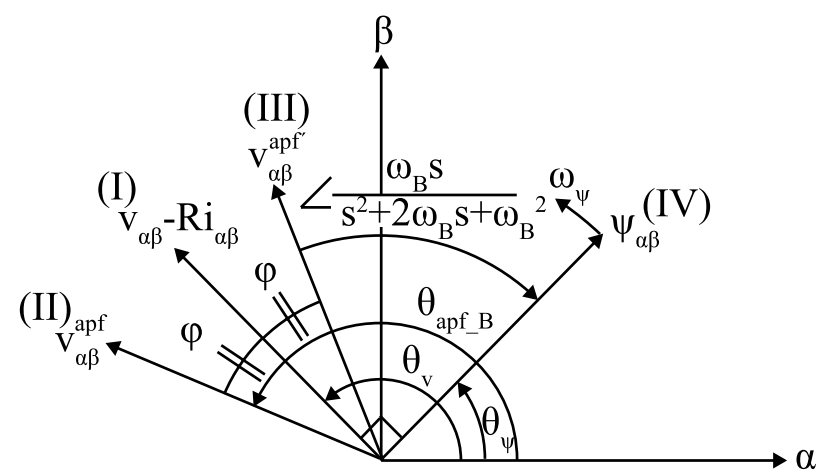

Fig. 11. Coordinate of stator flux estimator with APF based on BPF in stationary reference frame

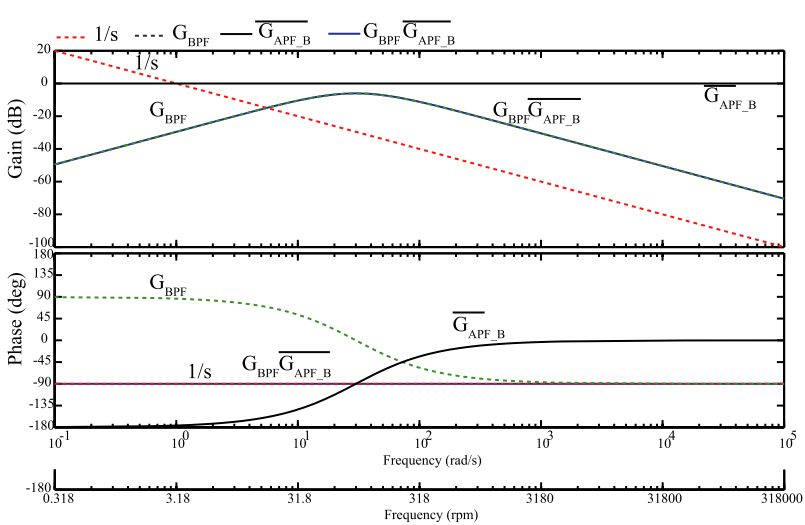

Fig. 12. Bode diagram of the stator flux estimator of using APF based on BPF

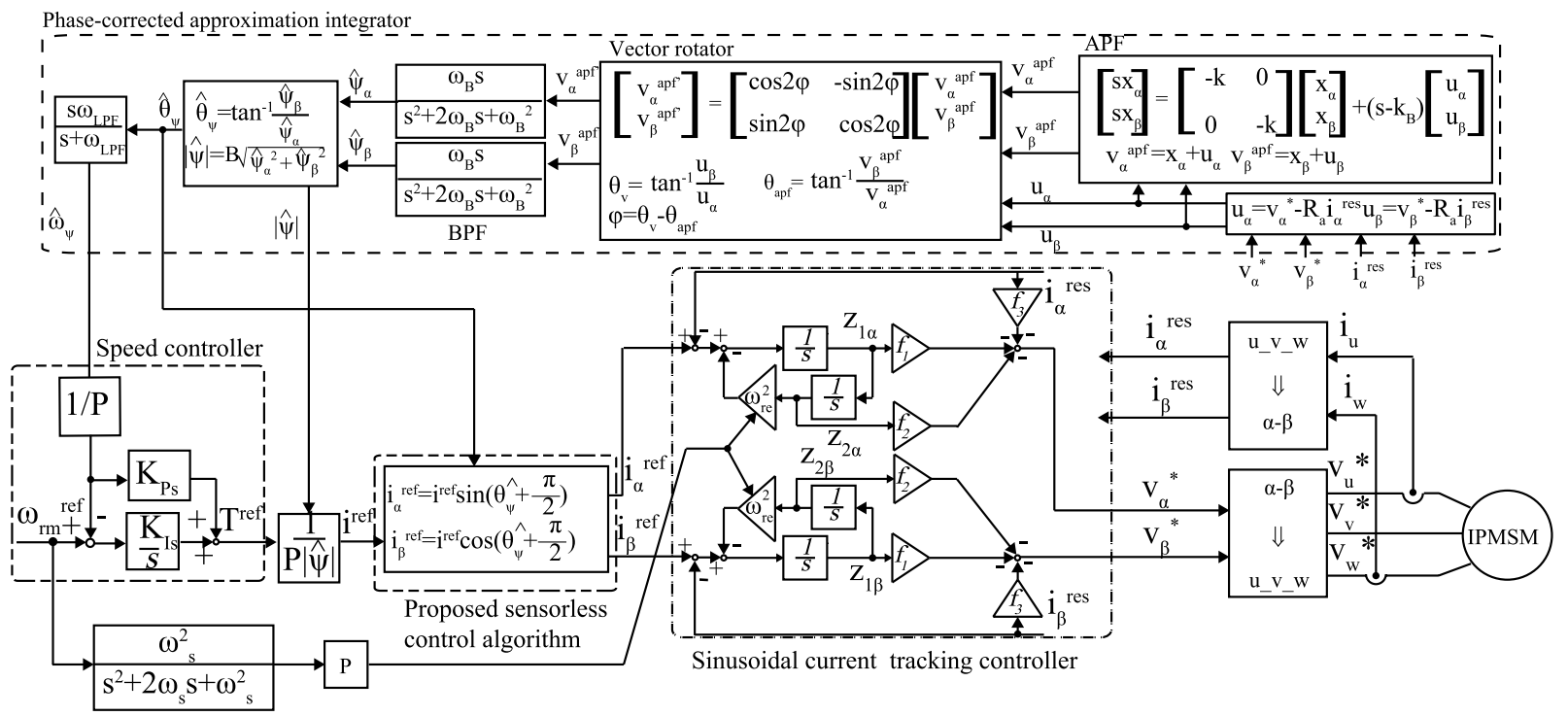

Fig. 13. Proposed position sensorless speed control system using sinusoidal current tracking controller without flux control loop (Method 1) 


$$
\frac{\omega_{r m}^{r e s}(s)}{\omega_{r m}^{r e f}(s)}=\frac{\omega_{s}^{2}}{s^{2}+2 \omega_{s} s+\omega_{s}^{2}}
$$

where $\mathrm{B}$ is a correction equation of the gain characteristic. As the DC gain of BPF becomes $-\infty$ as shown in Fig. 12, the offset of the current sensor is completely attenuated. In addition, the gain characteristic in Fig. 12 is affected by the angular frequency of the BPF. The phase characteristic in Fig. 12 is not affected by the angular frequency of the BPF. In addition, the phase characteristic is equal to an ideal integrator.

Therefore, this paper realizes the proposed position sensorless speed control system using the new sinusoidal current tracking controller as shown in Fig. 12, which is Method 1 of this paper. The control system of Method 1 is composed of only a stationary reference frame. Therefore, this control system does not require a coordinate transformation into a rotating coordinate. This is because it converts the output of the speed controller to the current command on the stationary reference frame by (34)-(36). The Method 1 control system does not require coordinate transformation to a rotating coordinate because it does not depend on the phase estimation accuracy.

(51) is obtained by using the angular frequency of the speed control system from (27). (51) is used for the internal model of the sinusoidal tracking current controller.

3.3 Sensorless Control Method of Torque and Flux (Method 2) In high-speed region of operation, it is necessary to carry out a flux-weakening control. To control the stator flux, this paper perform the coordinate conversion from $\alpha-\beta$ axis to M-T axis ${ }^{(15)(16)}$. The proposed magnetic flux controller is shown in Fig. 14. The current references $i_{M}^{r e f}$ and $i_{T}^{r e f}$ in Method 2 is changed into $i_{\alpha}^{r e f}$ and $i_{\beta}^{r e f}$ as shown in (53). As the result, Fig. 15 shows the proposed position sensorless speed and flux control system using new sinusoidal current tracking controller, which is Method 2 of this paper. On condition of $i_{M}^{\text {ref }}=0$ and $i_{T}^{\text {ref }}=i^{\text {ref }}$, (53) becomes (54). Therefore, on condition of on $i_{M}^{r e f}=0$ in Method 2, Method 2 becomes equivalent equal to Method 1.

$$
\begin{aligned}
{\left[\begin{array}{c}
i_{\alpha}^{r e f} \\
i_{\beta}^{r e f}
\end{array}\right] } & =\left[\begin{array}{cc}
\cos \hat{\theta}_{\psi} & -\sin \hat{\theta}_{\psi} \\
\sin \hat{\theta}_{\psi} & \cos \hat{\theta}_{\psi}
\end{array}\right]\left[\begin{array}{c}
i_{M}^{r e f} \\
i_{T}^{r e f}
\end{array}\right] \\
& =\left[\begin{array}{c}
i_{M}^{r e f} \cos \hat{\theta}_{\psi}-i_{T}^{r e f} \sin \hat{\theta}_{\psi} \\
i_{M}^{r e f} \sin \hat{\theta}_{\psi}+i_{T}^{r e f} \cos \hat{\theta}_{\psi}
\end{array}\right] \\
& =\left[\begin{array}{c}
i_{M}^{r e f} \sin \hat{\theta}_{i}+i_{T}^{r e f} \cos \hat{\theta}_{i} \\
-i_{M}^{r e f} \cos \hat{\theta}_{i}+i_{T}^{r e f} \sin \hat{\theta}_{i}
\end{array}\right] \ldots \\
{\left[\begin{array}{c}
i_{\alpha}^{r e f} \\
i_{\beta}^{r e f}
\end{array}\right] } & =\left[\begin{array}{c}
i^{r e f} \cos \hat{\theta}_{i} \\
i^{r e f} \sin \hat{\theta}_{i}
\end{array}\right] \ldots \ldots \ldots \ldots \ldots
\end{aligned}
$$

\section{Experimental Results}

This paper confirms the validity of the proposed methods by the experimental results. Table 3 shows the angular frequency of the controller and the carrier frequency used in the experiment.

4.1 Experimental Results of Speed Control Figures 16 and 17 show the experimental results of sensorless speed control IPMSM, whose flux current condition is zero. Figure 16 shows the experimental results of Method 1. Figure 17 shows the experimental results of Method 2 on condition that $i_{M}^{r e f}=0$. The poles of tested current control system of Method 1 and Method 2 are designed to 2,000 rad/s ${ }^{(13)(14)}$. Figures 16 and 17 confirm that Method 1 and Method 2 of the proposed sensorless speed control systems have stable speed and torque responses. Moreover, both speed responses of Method 1 and Method 2 are almost the same as those of Fig. 8, which are the speed responses of a speed control system with a position sensor. However, the ripple of $i^{\text {ref }}$ during

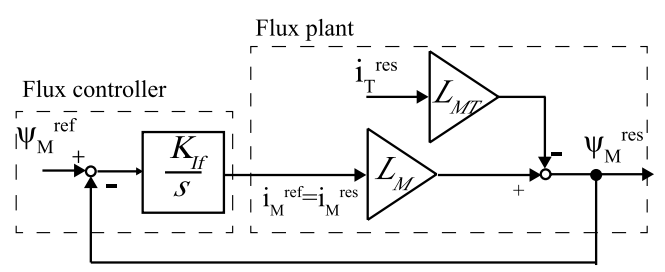

Fig. 14. Flux control loop of Method 2

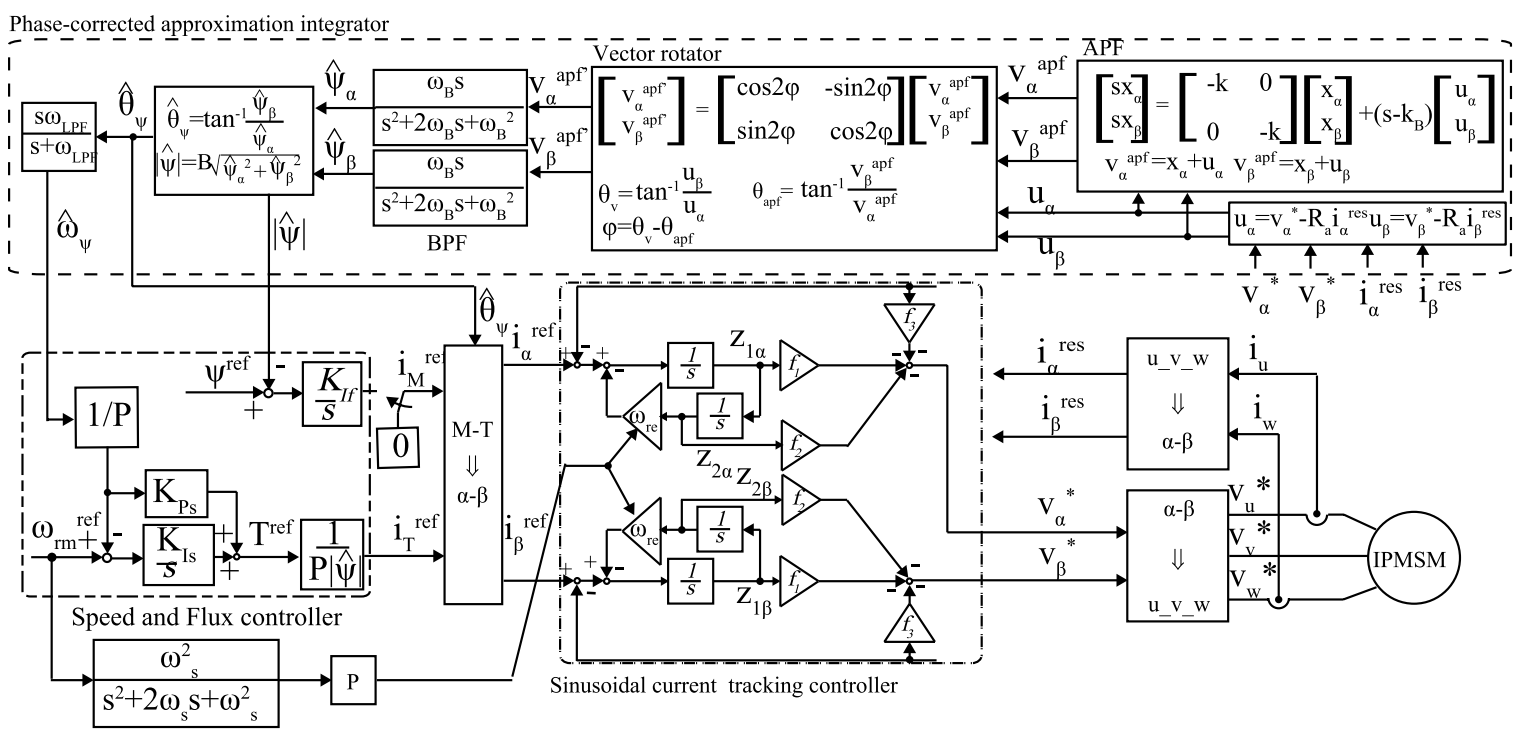

Fig. 15. Proposed position sensorless speed and flux control system using sinusoidal current tracking controller (Method 2) 
Table 3. Motor parameters and simulation conditions

\begin{tabular}{|c|c|c|}
\hline Poles of the speed control system & $\omega_{s}$ & $80[\mathrm{rad} / \mathrm{s}]$ \\
\hline Poles of the flux control system & $\omega_{f}$ & $80[\mathrm{rad} / \mathrm{s}]$ \\
\hline Poles of the current control system & $\omega_{c}$ & $2000[\mathrm{rad} / \mathrm{s}]$ \\
\hline Cut-off frequency of low-pass filter & $\omega_{L P F}$ & $640[\mathrm{rad} / \mathrm{s}]$ \\
\hline Pole of band-pass filter & $\omega_{B}$ & $10[\mathrm{rad} / \mathrm{s}]$ \\
\hline Carrier frequency & $f_{s}$ & $10[\mathrm{kHz}]$ \\
\hline
\end{tabular}

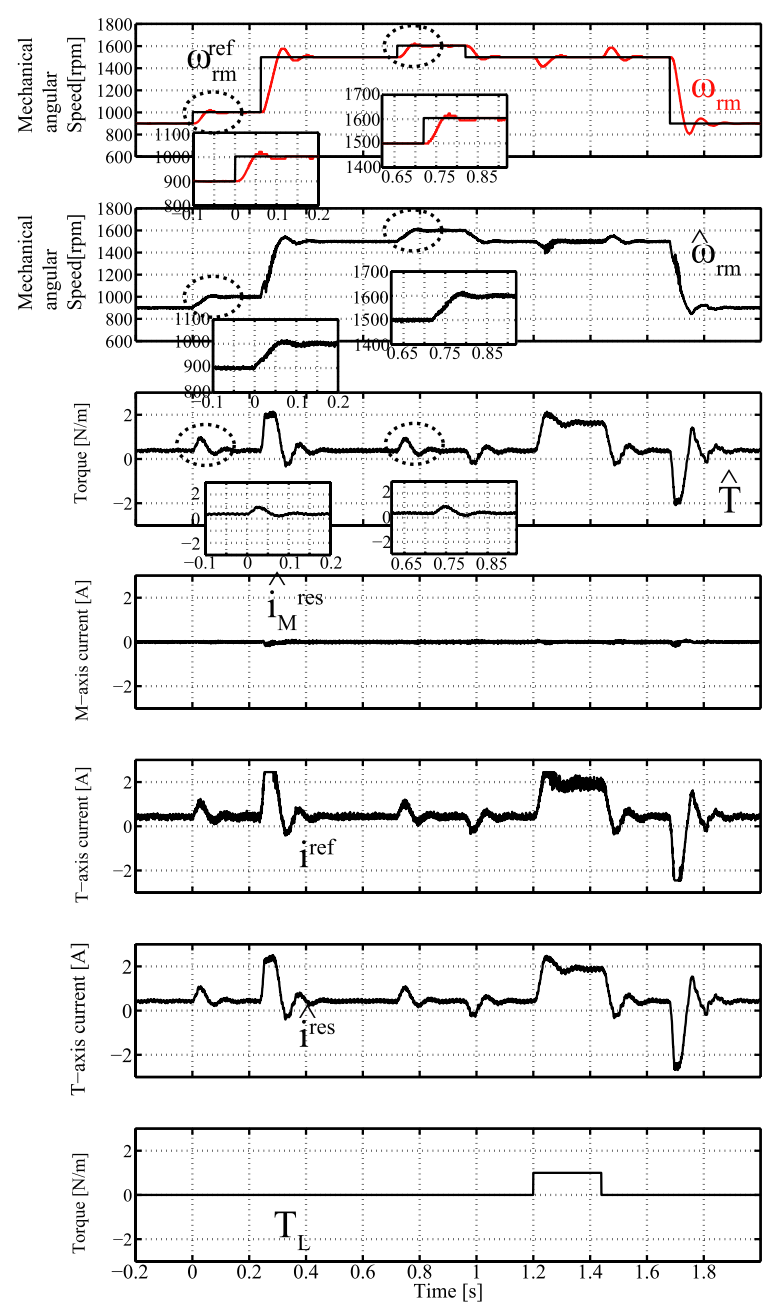

Fig. 16. Experimental results of speed step response in Method 1

the $1.2-1.4 \mathrm{~s}$ interval is larger than at any other time. The reason for this is that the phase estimation value of the stator flux linkage by the load torque becomes oscillatory.

Figure 18 shows that the experimental results of step speed response of Method 2 from $-700 \mathrm{rpm}$ to $700 \mathrm{rpm}$. Figure 18 confirms that the proposed sensorless speed control system well regulates the motor speed throughout zero speed area.

4.2 Experimental Results of Flux-weakening Control

When the voltage vector becomes larger than $V_{\text {max }}$, the stator flux command ${ }^{(4)}$ is determined by (55). $V_{\max }$ is the maximum voltage of inverter.

$$
\psi^{r e f}=\frac{-R_{a} i_{T}+\sqrt{V_{\max }^{2}-\left(R_{a} i_{M}\right)^{2}}}{\hat{\omega}_{\psi}}
$$

In this paper, the tested PWM inverter has the triangular wave comparison modulation method. Therefore, the maximum voltage of tested the inverter is given by (56).

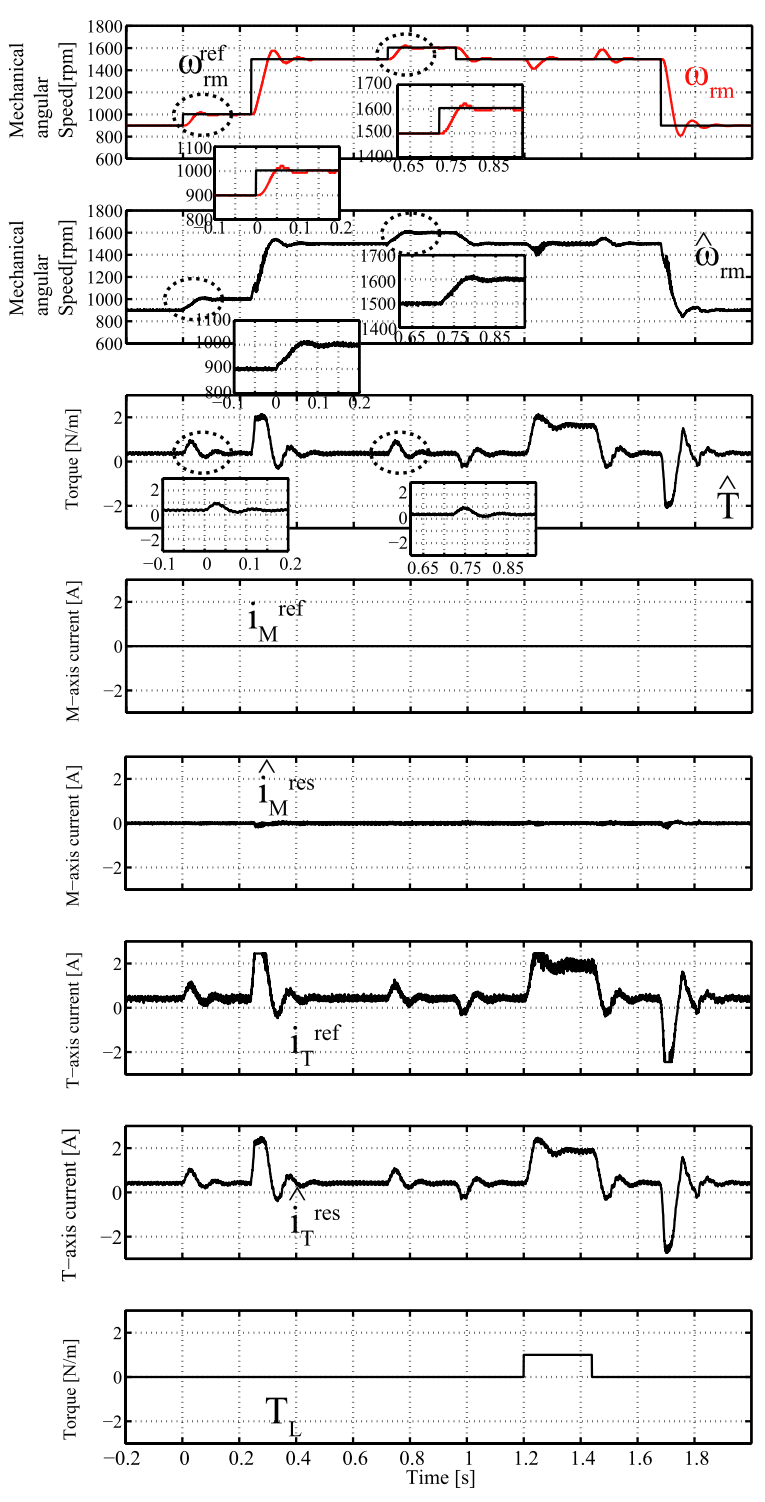

Fig. 17. Experimental results of speed step response on condition of $i_{M}^{r e f}=0$ in Method 2

$$
V_{\text {max }}=\frac{1}{2} \sqrt{\frac{3}{2}} V_{d c}
$$

To confirm the effectiveness of the flux-weakening control, Fig. 19 shows the experimental results of acceleration experiment for the voltage saturation region. $V_{d c}$ is set to $200 \mathrm{~V}$. The experimental results confirm that the proposed flux weakening control has the fine and stable flux control response as shown in Fig. 19. The proposed sensorless speed control system well regulates the motor speed in the region of voltage saturation. Therefore, the proposed flux-weakening control has the stable speed response in the region of voltage saturation.

\section{Conclusion}

This paper proposes a new stationary reference frame position sensorless control based on stator flux linkage and new sinusoidal current tracking controller for IPMSM.

At first, this paper proposes a new sinusoidal current tracking controller and carries out its performance analysis based 


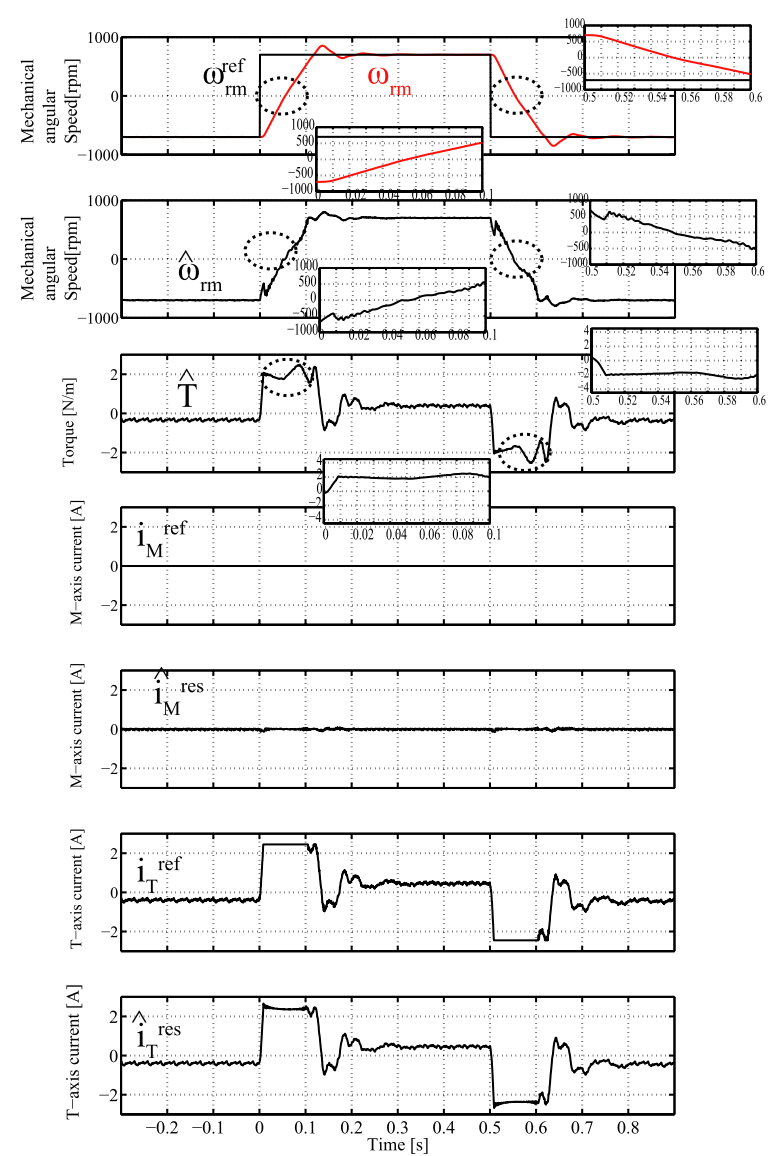

Fig. 18. Experimental results of speed step response from $-700 \mathrm{rpm}$ to $700 \mathrm{rpm}$ on condition of $i_{M}^{\text {ref }}=0$ in Method 2

on the extended transformation. This analysis points out the harmonic disturbance suppression performance of $\alpha-\beta$ sinusoidal current controller. The numerical simulation results and experimental results confirm that the disturbance suppression characteristics of new $\alpha-\beta$-sinusoidal current tracking controller is higher than that of d-q PI current controller.

Next, this paper newly proposes the two types of position sensorless control systems based on the proposed sinusoidal current tracking controller. Method 1 is the position sensorless control method. Method 2 is the position sensorless speed control of both stator flux and torque. The experimental results confirm that Method 1 and Method 2 have stable speed and torque responses. Moreover, the flux-weakening control of Method 2 is well achieved. Since the proposed flux-weakening control in Method 2 has no information of inductance parameters, it has a fine stator flux control in the region of voltage saturation.

\section{References}

( 1 ) I. Takahashi and T. Noguchi: "A new quick-response and high-efficiency control strategy of an induction motor", IEEE Trans. on Industry Applications, Vol.22, No.5, pp.820-827 (1986)

( 2 ) F. Niu, K. Li, and Y. Wang: "Direct Torque Control for Permanent-Magnet Synchronous Machines Based on Duty Ratio Modulation", IEEE Trans. on Industrial Electronics, Vol.62, No.10, pp.6160-6170 (2015)

( 3 ) Y. Inoue, S. Morimoto, and M. Sanada: "A Reference Value Calculation
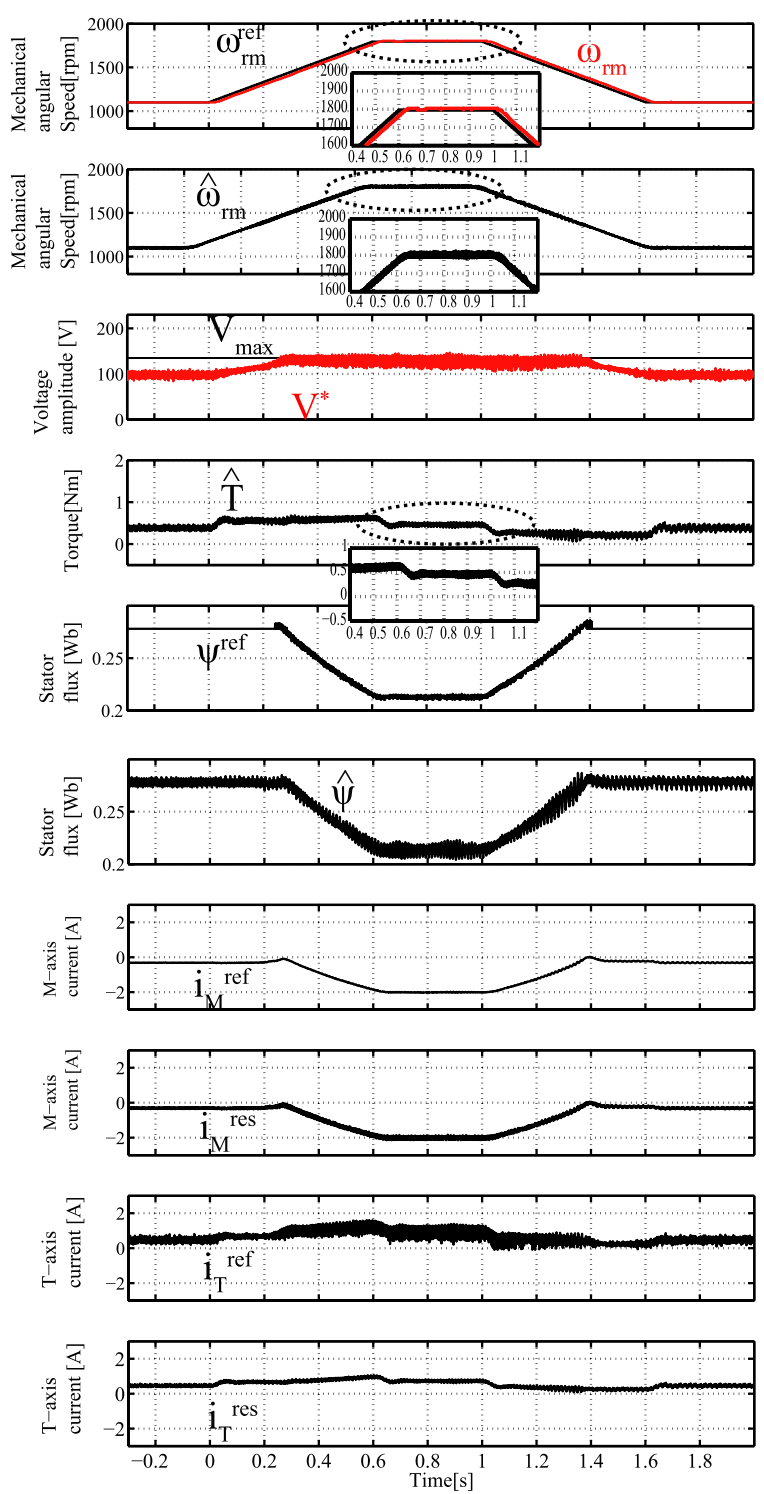

Fig. 19. Experimental results of acceleration control with flux weakening control in Method 2

Scheme for Torque and Flux and an Anti-Windup Implementation of Torque Controller for Direct Torque Control of Permanent Magnet Synchronous Motor", IEEE Trans. on Industry Applications, Vol.130, No.6, pp.777-784 (2010)

( 4 ) T. Inoue, Y. Inoue, S. Morimoto, and M. Sanada: "Mathematical Model and Control Method of Maximum Torque Per Ampere for PMSM in Stator Flux Linkage Synchronous Frame", IEEJ Trans. on Industry Applications, Vol.135, No.6, pp.689-696 (2015)

( 5 ) M.-H. Shin, D.-S. Hyun, S.-B. Cho, and S.-Y. Choe: "An Improved Stator Flux Estimation for Speed Sensorless Stator Flux Orientation Control of Induction Motors", IEEE Trans. on Power Electronics, Vol.15, No.2, pp.312318 (2000)

( 6 ) T. Murata, T. Tsuchiya, and I. Takeda: "Vector Control for Induction Machine by Primary Flux Linkage Control", Trans. of the Society of Instrument and Control Engineers, Vol.25, No.11, pp.1194-1201 (1989)

( 7 ) R. Takahashi and K. Ohishi: "Vector control using a Sinusoidal Current Tracking Controller in Stationary Reference Frame for SPMSM", The Papers of Technical Meeting on Mechatronics Control, IEE Japan, Vol.14, No.162, pp.17-22 (2014) (Japanese)

( 8 ) S. Ichikawa, M. Tomita, S. Doki, and S. Okuma: "Sensorless Control of Synchronous Reluctance Motors Based on Extended EMF Models Considering Magnetic Saturation With Online Parameter Indentification”, IEEE Transactions on Industry Applications, Vol.42, No.5, pp.1264-1274 (2006)

( 9 ) H. Nakano, H. Eda, M. Naitoh, Y. Yamamoto, R. Kondo, and J. Shimizu: "Novel Analysis Method Based on Extended Bode Diagram for High-pass 
Filter Using Rotating Coodinate Transformations", IEEJ Trans. IA, Vol.119D, No.2, pp.175-181 (1999)

(10) H. Nakano, M. Jibiki, A. Nabae, and Y. Okamura: "Variable Frequency Inverter with Sinusoidal Voltage Outputs Using Rotating Coordinate Transformation”, IEEJ Trans. IA, Vol.115-D, No.6, pp.735-742 (1995)

(11) R. Takahashi, K. Ohishi, H. Haga, and Y. Yokokura: "Vector control using a Sinusoidal Current Tracking Controller in Stationary Reference Frame for IPMSM", The Papers of Joint Technical Meeting on Semiconductor Power Converter and Motor Drive, IEE Japan, Vol.15, No.25, pp.149-154 (2015) (Japanese)

(12) R. Takahashi, K. Ohishi, H. Haga, and Y. Yokokura: "Stationary reference frame sensorless vector control based on primary flux linkage and sinusoidal complete tracking current controller for IPMSM", Proc. of IECON 2015 41st Annual Conference of the IEEE Industrial Electronics Society, pp.2006$2011(2015)$

(13) K. Tanaka, M. Hasegawa, and A. Matsumoto: "Position Estimation Using All-pass Filter for PMSM Position Sensorless Control", The Papers of Joint Technical Meeting on Semiconductor Power Converter and Motor Drive, IEE Japan, Vol.15, No.46, pp.101-106 (2015) (Japanese)

(14) K. Tanaka, M. Hasegawa, and A. Matsumoto: "Extremely Precise Position Estimation Using All-pass Filter and BPF for PMSMs Postion Sensorless Control", The Papers of Joint Technical Meeting on Semiconductor Power Converter and Motor Drive, IEE Japan, Vol.15, No.121, pp.13-18 (2015) (Japanese)

(15) R. Takahashi, K. Ohishi, H. Haga, and Y. Yokokura: "Vector control using a Sinusoidal Current Tracking Controller in Stationary Reference Frame for IPMSM", The Papers of Joint Technical Meeting on Semiconductor Power Converter and Motor Drive, IEE Japan, Vol.15, No.98, pp.51-56 (2015) (Japanese)

(16) R. Takahashi, K. Ohishi, H. Haga, and Y. Yokokura: "Position Sensorless Speed Control Based on Stator Flux Linkage and Stationary Reference Frame for IPMSM(Second report)", The Papers of Joint Technical Meeting on Semiconductor Power Converter and Motor Drive, IEE Japan, Vol.16, No.8, pp.43-48 (2016) (Japanese)

\section{Appendix}

\section{Extended Transfer Function}

In order to confirm the effectiveness of the $\alpha-\beta$ sinusoidal current control, it is compared with the current control system on a $d-q$ synchronous frame, whose name is $d$ - $q$ PI current control. The input and output frames of $d-q$ PI current control are different from them of $\alpha-\beta$ sinusoidal current control. In order to analyze the performance of $d-q$ PI current control, this paper uses the rotating coordinate transformation $\mathrm{e}^{j \omega_{r e} t}$ and $\mathrm{e}^{-j \omega_{r e} t(9)(10)}$. The $d-q$ PI current control is equivalently converted on $\alpha-\beta$ stationary frame.

app. Fig. 1 shows the extended transformation of the equivalent $d-q$ PI current controller on $\alpha-\beta$ stationary frame. In app. Fig. 1, the voltage reference on $\alpha-\beta$ stationary frame $v_{\alpha \beta}^{r e f}$ is defined in (A5). Furthermore, (A5) is rewritten as (A6).

$$
\begin{aligned}
& v_{\alpha \beta}^{r e f}=v_{\alpha}^{r e f}+j v_{\beta}^{r e f} . \\
& i_{\alpha \beta}^{e r r}=i_{\alpha \beta}^{r e f}-i_{\alpha \beta}^{r e s}=i_{\alpha}^{e r r}+j i_{\beta}^{\text {err }} \\
& T^{-1}=\left[\begin{array}{ll}
\cos \omega_{r e} t & j \sin \omega_{r e} t \\
j \sin \omega_{r e} t & \cos \omega_{r e} t
\end{array}\right]=\mathrm{e}^{j \omega_{r e} t} \ldots \\
& T=\left[\begin{array}{cc}
\cos \omega_{r e} t & -j \sin \omega_{r e} t \\
-j \sin \omega_{r e} t & \cos \omega_{r e} t
\end{array}\right]=\mathrm{e}^{-j \omega_{r e} t} \ldots \ldots \\
& {\left[\begin{array}{c}
v_{\alpha}^{r e f} \\
j v_{\beta}^{r e f}
\end{array}\right]=T^{-1}\left[\begin{array}{cc}
\frac{K_{P} s+K_{I}}{s} & 0 \\
0 & \frac{K_{P} s+K_{I}}{s}
\end{array}\right] T\left[\begin{array}{c}
i_{\alpha}^{e r r} \\
j i_{\beta}^{e r r}
\end{array}\right] .} \\
& \frac{v_{\alpha \beta}^{r e f}}{i_{\alpha \beta}^{e r r}}=\frac{K_{P}\left(s-j \omega_{r e}\right)+K_{I}}{s-j \omega_{r e}}
\end{aligned}
$$

Where, $K_{p}$ and $K_{i}$ are the $d-q$ PI current controller gains. app. Fig. 2 shows extended transformation of the equivalent

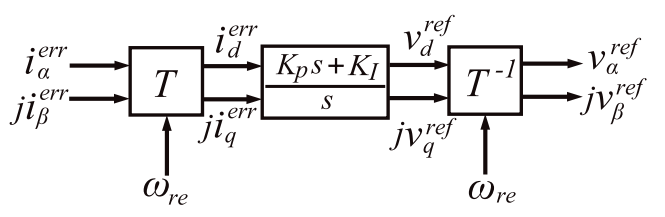

app. Fig. 1. Equivalent $d-q$ PI current controller on $\alpha-\beta$ stationary frame

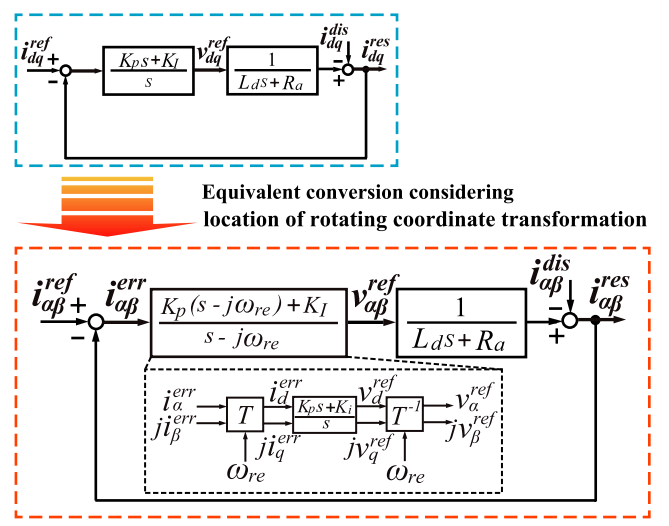

app. Fig. 2. Extended transformation of equivalent $d-q$ PI current control system on $\alpha-\beta$ stationary frame

app. Table 1. Different IPMSM parameters

\begin{tabular}{|c|c|}
\hline$R_{a}$ & $0.78[\Omega]$ \\
\hline$L_{d}$ & $6.43[\mathrm{mH}]$ \\
\hline$L_{q}$ & $10.37[\mathrm{mH}]$ \\
\hline$P$ & 5 \\
\hline$J_{M}$ & $3.3 * 10^{-4}\left[\mathrm{kgm}^{2}\right]$ \\
\hline
\end{tabular}

$d-q$ PI current control system on the $\alpha-\beta$ stationary frame. The transfer function to the current response $i_{\alpha \beta}^{r e s}$ from the disturbance $i_{\alpha \beta}^{d i s}$ is defined as (A7).

$$
\begin{aligned}
& G_{d q-P I}^{d i s}=\frac{i_{\alpha}^{r e s}}{i_{\alpha}^{d i s}}=\frac{-s^{2}+n_{1} s+n_{0}}{s^{2}+m_{1} s+m_{0}} \\
& m_{0}=\frac{K_{I}-j\left(R_{a}+K_{P}\right) \omega_{r e}}{L_{d}} \ldots \ldots \\
& m_{1}=\frac{\left(R_{a}+K_{P}-j L_{d} \omega_{r e}\right)}{L_{d}} \ldots \ldots \\
& n_{0}=\frac{j R_{a} \omega_{r e}}{L_{d}} \ldots \ldots \ldots \ldots \ldots \\
& n_{1}=\frac{-R_{a}+j L_{d} \omega_{r e}}{L_{d}} \ldots \ldots \ldots \ldots
\end{aligned}
$$

\section{Evaluation based on Extended Transformation of the Disturbance Suppression Characteristics}

The current control system using the sinusoidal tracking controller in the modified IPMSM obtained similar disturbance suppression characteristics as shown in Fig. 4. The current control system, in the case of the modified IPMSM shown in app. Table 1, obtained the disturbance suppression characteristics shown in app. Figs. 3 and 4. 


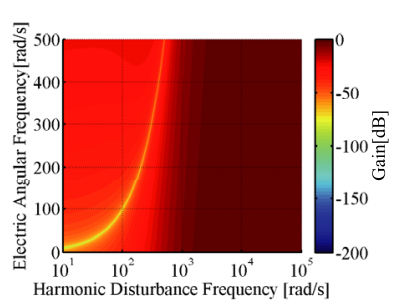

(a) Disturbance suppression characteristics of the positivephase harmonic components. app. Fig. 3. Disturbance suppression characteristics using d-q PI current control

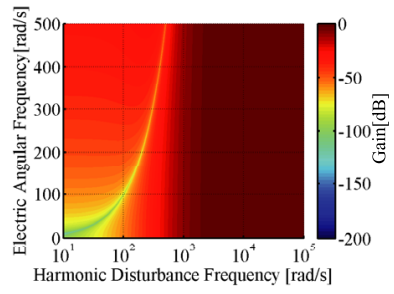

(a) Disturbance suppression characteristics of the positivephase harmonic components. app. Fig. 4. Disturbance suppression characteristics using $\alpha-\beta$ sin current control

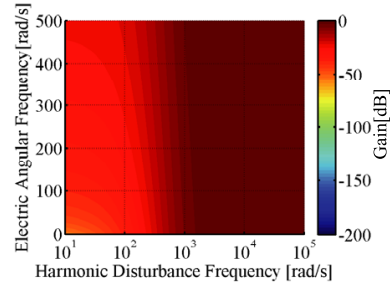

(b) Disturbance suppression characteristics of the negativephase harmonic components.

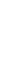

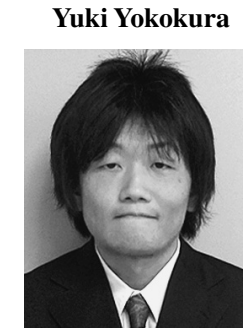

(Member) received his B.E. and M.E. degrees in electrical engineering from the Nagaoka University of Technology, Niigata, Japan, in 2007 and 2009, respectively. He received his Ph.D. degree in integrated design engineering from Keio University, Yokohama, Japan, in 2011. From 2010 to 2011, he was a JSPS research fellow (DC2 and PD). Since 2011, he was a visiting fellow at Keio University, and a postdoctoral fellow at Nagaoka University of Technology. Since 2012, he has been with Nagaoka University of Technology. His research interests include motion control, motor drive, power electronics, and real-world haptics.

Hitoshi Haga (Member) received B.S., M.S. and D.Eng. degrees in

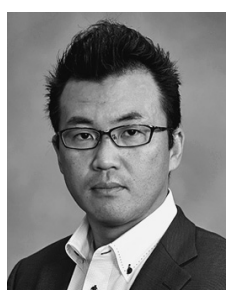
energy and environmental science from the Nagaoka University of Technology, Nagaoka, Japan, in 1999, 2001, and 2004, respectively. From 2004 to 2007, he was a Researcher with Daikin Industries, Ltd., Osaka, Japan. From 2007 to 2010, he was an Assistant Professor with the Sendsai National College of Technology, Sendai, Japan. Since 2010, he has been with the Department of Electrical Engineering, Nagaoka Uni-

power electronics. versity of Technology. His research interests include (b) Disturbance suppression characteristics of the negativephase harmonic components.
Tenjiroh Hiwatari (Student Member) received B.S. degree in Elec-

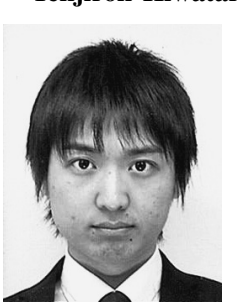
trical, Electronics and Information Engineering from Nagaoka University of Technology, Japan in 2016. Now he is a candidate of the M.S. degree in Electrical, Electronics and Information Engineering. His research interests include motor control. He is a student member of the Institute of Electrical Engineers of Japan (IEEJ).

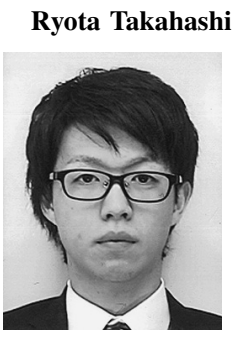

Student Member) received B.S. degree in Electrical, Electronics and Information Engineering from Nagaoka University of Technology, Japan in 2014. Now he is a candidate of the M.S. degree in Electrical, Electronics and Information Engineering. His research interests include motor control.
Kiyoshi Ohishi (Fellow) received the B.S., M.S., and Ph.D. degrees,

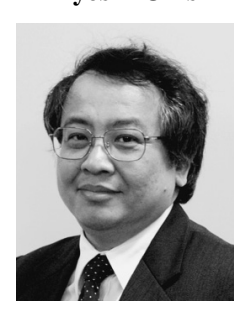
all in electrical engineering, from Keio University, Yokohama, Japan, in 1981, 1983, and 1986, respectively. From 1986 to 1993, he was an Associate Professor with Osaka Institute of Technology, Osaka, Japan. From 1993 to 2003, he was an Associate Professor with Nagaoka University of Technology, Niigata, Japan. Since August 2003, he has been a Professor at the same university. He is an administration committee member of the IEEE Industrial Electronics Society, the Institute of Electrical Engineers of Japan (IEEJ), the Japan Society of Mechanical Engineers (JSME), the Society of Instrument and Control Engineers (SICE), and the Robotics Society of Japan (RSJ). 